\title{
COMENTARIO A LA SENTENCIA \\ CORTE SUPREMA DE JUSTICIA - SALA CIVIL \\ SC20950 - 2017 \\ DICIEMBRE 12 DE 2017 \\ RADICACIÓN: 05001-31-03-005-2008-00497-01 \\ MAGISTRADO PONENTE: ARIEL SALAZAR RAMÍREZ ${ }^{*}$
}

MARIA CRISTINA ISAZA POSSE**

\section{EL CASO}

\section{Los hechos:}

1. Un automotor colisionó con una motocicleta conducida por un hombre de 32 años, casado y padre de una niña de 2 años, quien administraba un bar y restaurante de su propiedad, recibiendo unos ingresos mensuales.

2. Como consecuencia del accidente el conductor de la motocicleta sufrió graves lesiones y falleció al día siguiente.

3. La Secretaría de Tránsito y Transporte de la zona sancionó como responsable de contravención al conductor del vehículo, exonerando de culpa al conductor de la motocicleta.

4. El automotor estaba asegurado mediante una póliza de seguro.

* Reseña Jurisprudencial

** Abogada Universidad Javeriana. Especialista y Magistra en Derecho de Seguros, Universidad Javeriana.Asesora y Consultora. Profesora Universitaria. Contacto: mcisaza@isazaposse.com 
5. La esposa y la hija formularon la reclamación de los perjuicios sufridos a la aseguradora, quien objetó el pago y se rehusó a expedir copia del contrato de seguro.

\section{Primera instancia:}

Fue instaurada la demanda contra el responsable y contra la aseguradora. El asegurado a su vez, en la contestación de la demanda llamó en garantía a la aseguradora.

Se plantearon excepciones de mérito.

El asegurado demandado propuso las siguientes excepciones:

- Inepta demanda

- Culpa exclusiva de la víctima

- Concurrencia de culpas

La aseguradora propuso las siguientes excepciones:

Respecto de la responsabilidad del asegurado:

- Causa extraña

- Reducción del monto indemnizable en virtud del comportamiento culposo del fallecido.

- Colisión de actividades peligrosas

- Estimación excesiva del daño moral y del lucro cesante

Respecto de la cobertura del seguro:

- Ausencia de cobertura del lucro cesante

- Ausencia de cobertura del daño a la vida de relación como perjuicio 
extrapatrimonial.

- No estar obligada a asumir todos los costos del litigio

Solicitó tener por ineficaces las siguientes cláusulas:

- Límites a la indemnización

- Sublímite de indemnización en el caso del daño moral

Sentencia de Primera instancia:

Tuvo por demostrada la excesiva estimación del daño moral y el lucro cesante, desestimando las otras excepciones. Declaró civil y extracontractualmente responsable por los perjuicios al conductor del vehículo, condenándolo a él y a la aseguradora al pago del daño emergente pasado y "futuro", del lucro cesante consolidado y futuro, del daño moral y del daño a la vida de relación.

\section{Recurso de apelación:}

El demandado y la aseguradora formularon el correspondiente recurso de apelación.

\section{Sentencia de segunda instancia:}

El superior modificó la decisión desestimando las defensas dadas por establecidas en la primera instancia.

- Recalculó la suma del lucro cesante pasado y futuro en favor de la cónyuge y la hija.

- Incrementó la indemnización por daño a la vida de relación para ambas.

En lo demás confirmó la decisión haciendo la salvedad de que la responsabilidad de la aseguradora no es solidaria, sino contractual.

Fundamentos de la sentencia de segunda instancia: 
1. En relación con los hechos declaró responsable al conductor del vehículo sin que obrara prueba de culpa del conductor de la motocicleta.

2. En lo relacionado con la exclusión del lucro cesante, determina que ésta no es aplicable por cuanto en la póliza se excluye el lucro cesante que no sea consecuencia directa de un daño material o personal cubierto por el seguro. En este caso resulta ser consecuencia directa de la muerte del conductor de la motocicleta.

3. De conformidad con lo establecido por el artículo 1127 del Código de Comercio, el seguro de responsabilidad civil impone a cargo del asegurador la obligación de indemnizar los perjuicios patrimoniales causados por el asegurado y tiene como propósito el resarcimiento de la víctima. Los perjuicios extrapatrimoniales que sufra la víctima "toman la connotación de materiales, pues para el asegurado conllevan una merma patrimonial cuando surge el deber de reparar".

4. El acápite final de las exclusiones consignadas en la póliza dispone el pago de los perjuicios extrapatrimoniales cuando éstos sean tasados en sentencia judicial en firme.

5. Da plena validez a la certificación del contador para acreditar el monto de los ingresos base de liquidación.

6. Aplica una deducción del $50 \%$ por concepto de gastos personales sobre los ingresos para calcular el lucro cesante, tomando en consideración que la cónyuge es una profesional en contaduría pública y aportaba ingresos para el funcionamiento del hogar. Establece el periodo indemnizable de la hija hasta los 25 años.

7. La indemnización por concepto de daño moral no es desproporcionada, pero la indemnización por daño a la vida de relación debe reajustarse en vista de las consecuencias sufridas por la esposa y la hija como consecuencia de la falta de la figura paterna.

8. La aseguradora no está llamada a responder por la condena de forma solidaria, sino en virtud de la obligación contractual derivada del contrato de seguro celebrado. 


\section{Demanda de casación:}

Se formularon 8 cargos parciales contra la sentencia de segunda instancia, los cuales no discuten la existencia del hecho dañoso, la responsabilidad del causante del daño, la estimación del daño emergente y moral, ni la forma en que deben asumir el pago los demandados. Todos se plantean por la causal primera del artículo 368 del Código de Procedimiento Civil.

Los cargos formulados son los siguientes:

- $\left(1^{\circ}\right)$ violación indirecta de los artículos 16 de la Ley 446 de 1998, 1613 y 1614 del Código Civil al otorgarle valor probatorio al certificado expedido por el contador público y dar por establecido el ingreso mensual promedio de la víctima.

- $\left(2^{\circ}\right)$ violación indirecta de los artículos 16 de la Ley 446 de 1998, 1613 y 1614 del Código Civil al valorar las probanzas de donde extrajo la base para liquidar el lucro cesante.

- $\left(3^{\circ}\right)$ violación indirecta de los artículos 16 de la Ley 446 de 1998, 2341 y 2343 del Código Civil como consecuencia de errores en la valoración probatoria, que condujeron a tener por demostrado el daño a la vida de relación sufrido por los demandantes.

- (4º) violación directa de los artículos 16 de la Ley 446 de 1998, 1613, 1614, 2341 y 2343 del Código Civil al liquidar el lucro cesante.

- $\left(5^{\circ}\right)$ Violación directa de los artículos 1056 y 1127 del Código de Comercio por falta de aplicación e interpretación errónea, al estimar que "el seguro de responsabilidad civil, salvo exclusión expresa, ampara los perjuicios extrapatrimoniales sufridos por la víctima, pues estos tienen la connotación de daños materiales para el asegurado". Con ello se desfigura el sentido del artículo 1127 que ordena indemnizar solo los patrimoniales, con extensión a los extrapatrimoniales si se pactan expresamente.

- $\left(6^{\circ}\right)$ infracción indirecta de los artículos 1602 y 1618 del Código Civil y 1056 y 1127 del Código de Comercio por errores de hecho en la valoración de las condiciones generales del contrato de seguro que llevaron 
a deducir que la cobertura para daños morales incluía el daño a la vida de relación sin que éste se hubiere pactado.

- $\left(7^{\circ}\right)$ acusación por violación directa con idénticos reproches a los formulados en el cargo quinto $\left(5^{\circ}\right)$ y violación indirecta de los artículos 1602 y 1618 del Código Civil y 1056 y 1127 del Código de Comercio.

- $\left(8^{\circ}\right)$ violación indirecta de los artículos 1602 y 1618 del Código Civil y 1056 del Código de Comercio por indebida interpretación del contrato de seguro al no dar por cierto que el contrato de seguro celebrado excluye el lucro cesante sufrido por los demandantes.

\section{Consideraciones de la Corte:}

La Corte con fines prácticos, resuelve los cargos en distinto orden.

En cuanto se refiere a los cargos quinto y séptimo:

Violación directa de los artículos 1056 y 1127 del Código de Comercio por falta de aplicación e interpretación errónea, al estimar que "el seguro de responsabilidad civil, salvo exclusión expresa, ampara los perjuicios extrapatrimoniales sufridos por la víctima, pues estos tienen la connotación de daños materiales para el asegurado". Con ello se desfigura el sentido del artículo 1127 que ordena indemnizar solo los patrimoniales, con extensión a los extrapatrimoniales si se pactan expresamente.

1. Los seguros de daños tienen por objeto la protección del patrimonio del asegurado y son de mera indemnización. Por medio de ellos, el asegurado busca la reparación de los efectos que produzca el siniestro en su patrimonio.

2. Estos seguros pueden ser reales o patrimoniales. Aunque ambos seguros son diferentes y se encuentran regulados por normativas independientes, a ambos se aplica el principio indemnizatorio.

3. El seguro de responsabilidad civil se encuentra regulado de manera especial en los artículos 1127 a 1133 del Código de Comercio, el artículo $4^{\circ}$ de la Ley 389 de 1997 y las disposiciones que crearon modalidades de seguros obligatorios para ciertos sectores de la economía o actividades específicas. 
Por lo anterior, a este tipo de seguro no se aplican las disposiciones legales que regulan otras categorías, ni aquellas que, aun siendo comunes a los seguros de daños, entran en contradicción con las normas especiales que lo gobiernan.

Tratándose del seguro de responsabilidad civil debe aplicarse el artículo 1127 del Código de Comercio, norma especial que consagra de modo expreso que los perjuicios que debe indemnizar la aseguradora son los "patrimoniales que cause el asegurado con motivo de determinada responsabilidad en que incurra". Se trata de una norma especial y ulterior prevalente de acuerdo con las normas relativas a la aplicación de la ley.

4. Pasa luego la Corte a estudiar los siguientes puntos:

a. El seguro de responsabilidad civil y su evolución normativa:

Señala la Corte la reforma introducida mediante la Ley 45 de 1990, poniendo de presente que "bajo su concepción original, el fin primordial de ese convenio radicaba en la indemnización al asegurado de los eventuales perjuicios derivados de sus actuaciones. El móvil de éste para contratar no era otro que el de evitar las pérdidas económicas que llegara a sufrir en caso de resultar responsable civilmente ante otras personas, y se viera conminado a efectuar erogaciones en favor de éstas a fin de resarcir los daños que les hubiera causado."

Mediante la reforma introducida por la Ley 45 de 1990 a su originaria función de protección del patrimonio del asegurado, se adicionó la del resarcimiento de la víctima. Sin embargo, como se señaló en la exposición de motivos de dicha norma, la modificación introducida al artículo 1127 del Código de Comercio "no tuvo un propósito distinto al de garantizarle a la víctima el pago de los daños que le fueron irrogados", y por eso en virtud de la reforma, ella pasa a ser beneficiaria de la indemnización y titular de un mecanismo directo para obtener el resarcimiento.

"La función primigenia de esta tipología de seguro no fue suprimida ni alterada, pues el artículo 1083 del Código de Comercio vincula el interés asegurable al patrimonio del asegurado, el cual puede resultar afectado por la ocurrencia de hechos u omisiones por las cuales sea llamado a responder, 
de ahí que únicamente él sea su titular, condición objetiva que la inserción normativa del propósito de reparación del ofendido no modificó, como tampoco sufrió alteración el riesgo asegurable que continúa siendo el mismo.

Esa ha sido la posición de esta Sala, para la cual la modificación legal no alteró el objeto ni la finalidad propia del seguro de responsabilidad civil.”

"De modo que una interpretación de la regulación del seguro de responsabilidad civil que desconozca, suprima o aminore su función originaria en cuanto a la protección patrimonial del asegurado, desnaturalizaría el contenido esencial de dicho convenio y particularmente la función con la que fue concebido por la ley, en demérito de la confianza que el asegurado deposita al acudir a esa modalidad de aseguramiento."

b. Tipología de los daños que causa el asegurado:

"Cuando las normas de responsabilidad extracontractual aluden a la indemnización en favor de la víctima, es claro que se refieren al resarcimiento de la totalidad de los daños que infirió la conducta o actividad atribuida al responsable, sean ellos de orden patrimonial o extrapatrimonial."

La valoración de los daños debe atender al principio de reparación integral, conforme a lo dispuesto por el artículo 16 de la Ley 446 de 1998. De ahí que la obligación del juzgador sea la de ordenar la indemnización plena de los perjuicios sufridos por el damnificado.

"Mas, no es menos cierto que los perjuicios que el demandado causa a la víctima le generan un detrimento económico al tener que pagar la condena a indemnizar integralmente los daños que causa al demandante; luego, constituye el mismo menoscabo pecuniario que el asegurado sufre al tener que solventarlos de su patrimonio. Por consiguiente, cuando la norma en comento alude a "los perjuicios patrimoniales que cause el asegurado" no se está refiriendo a la clasificación de los perjuicios (patrimoniales y extrapatrimoniales) dentro de la relación jurídica sustancial entre demandante y demandado en el proceso de responsabilidad civil, sino del detrimento económico que surge para el asegurado dentro de la relación que nace en virtud del contrato de seguro, los cuales son 
siempre de carácter patrimonial para el asegurado, independientemente de la tipología que se les haya asignado al interior del proceso de responsabilidad civil."

"En consecuencia, los daños a reparar (patrimoniales y extrapatrimoniales) estructuran un detrimento netamente patrimonial en la modalidad de daño emergente para la persona a la que le son jurídicamente atribuibles, ..."

"Por tal razón no puede decirse que el amparo por los "perjuicios extrapatrimoniales" de la víctima debe estar expresamente contemplado en la póliza como resultado de una lectura simplista del precepto y en desarrollo de la libertad contractual, ya que darle ese alcance restrictivo sería ir en contra del querer del legislador y de los fines que inspiraron la reforma."

En cuanto se refiere al cargo sexto y la acusación de violación indirecta del cargo séptimo:

Infracción indirecta de los artículos 1602 y 1618 del Código Civil y 1056 y 1127 del Código de Comercio por errores de hecho en la valoración de las condiciones generales del contrato de seguro que llevaron a deducir que la cobertura para daños morales incluía el daño a la vida de relación sin que éste se hubiere pactado.

"El contrato de seguro debe interpretarse en forma similar a las normas legales. La Sala ha sostenido que "el contrato de seguro es de interpretación restrictiva y por eso en su ámbito operativo, para determinar con exactitud los derechos y las obligaciones de los contratantes, predomina el texto de la que suele denominarse "escritura contentiva del contrato"."

"Bajo la anterior perspectiva, es claro que al momento de interpretar el contrato de seguro, el juzgador a la par que debe atender lo allí expresado, se le impone resguardar la función propia de la clase de relación asegurativa de que se trate, en donde antes que privilegiar el apego absoluto a cláusulas insularmente consideradas, debe propenderse por armonizarlas con el sentido general del que derivan su razón de ser en el contexto contractual. 
Resulta intrascendente la discusión en cuanto a que los daños a la vida de relación se tomaran como análogos a los daños morales por cuanto ambos harían parte de la obligación de la aseguradora, por encajar dentro del concepto de daños "que cause el asegurado".

En lo relacionado con el cargo tercero:

Violación indirecta de los artículos 16 de la Ley 446 de 1998, 2341 y 2343 del Código Civil como consecuencia de errores en la valoración probatoria, que condujeron a tener por demostrado el daño a la vida de relación sufrido por los demandantes.

"1. El daño no patrimonial -sostuvo esta Sala- se puede presentar de varias maneras, a saber: i) mediante la lesión a un sentimiento interior y, por ende, subjetivo (daño moral); ii) como privación objetiva de la facultad de realizar actividades cotidianas tales como practicar deportes, escuchar música, asistir a espectáculos, viajar, leer, departir con los amigos o la familia, disfrutar el paisaje, tener relaciones íntimas, etc., (daño a la vida de relación); o, iii) como vulneración a los derechos humanos fundamentales como el buen nombre, la propia imagen, la libertad, la privacidad y la dignidad, que gozan de especial protección constitucional (CSJ SC10297-2014, 5 ago. 2014, Rad. 2003-00660-01).

"Si bien las «subespecies del daño extrapatrimonial no pueden confundirse entre sí, pues cada una de ellas posee su propia fisonomía y peculiaridades que las distinguen de las demás y las hacen merecedoras de tutela jurídica», eso no impide que como a menudo acontece «confluyan en un mismo daño por obra de un único hecho lesivo» (ibídem).

"Esa enunciación es el resultado de una evolución jurisprudencial trazada desde la providencia CSJ SC, 13 May. 2008, Rad. 1997-09327-01, donde se analizó a profundidad el concepto de «daño en la vida de relación» como una de las formas de perjuicios extrapatrimoniales con entidad suficiente para distinguirse de las demás, ..."

Fue así como en ese pronunciamiento se puntualizó que el «daño en la vida de relación» cuenta con las siguientes características o particularidades: 
a. tiene naturaleza extrapatrimonial o inmaterial.

b. adquiere trascendencia o se refleja sobre la esfera externa del individuo.

c. se manifiesta en impedimentos, exigencias, dificultades, privaciones, vicisitudes, limitaciones o alteraciones, temporales o definitivas, de mayor o menor grado, que él debe soportar o padecer, las cuales, en todo caso, no poseen un significado o contenido monetario, productivo o económico.

d. puede tener origen en la afectación de otros bienes intangibles de la personalidad o derechos fundamentales, e incluso en la de otro tipo de intereses legitimos;

e. según las circunstancias de cada caso, puede ser sufrido por la víctima directa de la lesión o por terceros que igualmente resulten afectados, como, verbigracia, el cónyuge, el compañero o la compañera permanente, los parientes cercanos o los amigos, o por aquélla y éstos;

f. su reconocimiento persigue una finalidad marcadamente satisfactoria, $y$

g. es una noción que debe ser entendida dentro de los precisos límites y perfiles enunciados, como un daño autónomo que se refleja en la afectación de la actividad social no patrimonial de la persona, vista en sentido amplio, sin que pueda pensarse que se trata de una categoría que absorbe, excluye o descarta el reconocimiento de otras clases de daño -patrimonial o extrapatrimonial- que posean alcance y contenido disímil, ni confundirlo con éstos, como si se tratara de una inaceptable amalgama de conceptos, puesto que una indebida interpretación conduciría a que no pudiera cumplirse con la reparación integral ordenada por la ley y la equidad, como infortunadamente ha ocurrido en algunos casos, en franco desmedro de los derechos que en todo momento han de asistir a las víctimas.

Para el efecto de obtener una verdadera satisfacción que mengüe esos resultados adversos, en el referido fallo se llamó la atención de los jueces en pro de que para identificarlo observaran «especial prudencia y sensatez, principalmente para evitar a toda costa que dicho perjuicio sea confundido con otro de diverso linaje o que un determinado agravio 
pueda llegar erradamente a ser indemnizado varias veces», procediendo «con sujeción al marco fáctico sustancial descrito en la causa petendi que sirva como soporte de las pretensiones y al resultado que arrojen los medios probatorios recaudados en el proceso».

Y en la fijación del quantum también se requiere mesura y cuidado «bajo el entendido de que ella no puede responder solamente a su capricho, veleidad o antojo, sino que debe guardar ponderado equilibrio con las circunstancias alegadas y demostradas dentro de la controversia, velando así porque no sea desbordada la teleología que anima la institución de la responsabilidad civil».

En la actualidad la jurisprudencia tiene decantado que el «daño moral»y el «daño a la vida de relación» son dos manifestaciones separadas de perjuicios inconfundibles para los fines de reparación, pues, mientras el primero se refiere al padecimiento interno del afectado con el hecho dañoso, el último se contrae a las secuelas que éste tenga en el desenvolvimiento social del lesionado, en vista de los cambios externos en su comportamiento.

Nada obsta para que la apatía y el alejamiento, fuera de entenderse como exteriorizaciones del dolor ocasionado con el hecho luctuoso, trasciendan a un desentendimiento de lo que pasa alrededor y una modificación de las condiciones de vida, como alteración consecuencial directa del daño.

Adicionalmente, a pesar de la individualización de esas dos clases de lesiones extrapatrimoniales, no pueden pasarse por alto las coincidencias al momento de percatarse de su existencia, siendo que en ambos casos cobran importancia las reglas de la experiencia del fallador y que son fijados por arbitrium iudicis.

En cuanto se refiere al cargo octavo:

Se atribuyó al ad quem la trasgresión indirecta de los artículos 1602 y 1618 del Código Civil y 1056 del de Comercio, como producto de una indebida interpretación de un aparte del contrato de seguro, al desconocer que «el seguro de responsabilidad civil expedido por la aseguradora 
excluye la cobertura del lucro cesante sufrido por las demandantes».

En el numeral 2.14 de las condiciones generales de la póliza -sostuvo la censura- figura que «el seguro no cubre: "El lucro cesante y los perjuicios patrimoniales puros que no sean consecuencia directa de un daño (material o personal) cubierto por este seguro», lo que entendió el juzgador como si excluyera «sólo el lucro cesante que no fuera consecuencia de un daño material o personal cubierto por el seguro» y amparara el que «sea producto de un daño a una cosa o a una persona», deformando su contenido.

El objeto de ese convenio -agregó- era dejar por fuera «dos tipos de perjuicios diferentes, a saber: (i) el lucro cesante, y (ii) los perjuicios patrimoniales puros que no sean consecuencia directa de un daño material o corporal cubierto por el seguro», unidos por una conjunción copulativa, sin que se califique el primero, pues, la «condición según la cual el daño no debe ser consecuencia de un daño material o personal, es predicable exclusivamente del segundo tipo de daños estipulados en la cláusula, esto es, los daños patrimoniales puros».

1. Las negociaciones en el derecho privado se rigen por lo que convienen expresamente los contratantes, prefiriéndose las estipulaciones negociales a cualquier norma supletoria e incluso a la costumbre mercantil, según lo previsto en el artículo $4^{\circ}$ del Código de Comercio.

Tratándose del contrato de seguro, en caso de ambigüedad o imprecisión en las estipulaciones, la hermenéutica que se les dé debe preferir, antes que la elusión de riesgos, unos efectos adversos a quien la redactó y favorecedores a la parte que adhiere al clausulado, con el fin de superar cualquier inequidad y evitar el abuso de la posición dominante de la compañía aseguradora, que debe actuar con lealtad en cuanto a la fijación del nivel de responsabilidad asumida de conformidad con el artículo 1056 del Código de Comercio.

Esa interpretación acompasa con el tenor literal del numeral, donde no se vislumbra con claridad y precisión que, como sugiere la impugnante, el «lucro cesante» es absoluto y el calificativo de que no fueran «consecuencia directa de un daño» correspondiera solamente a los «perjuicios patrimoniales puros»». 
La falta de signos de puntuación o el que no fuera tratado el «lucro cesante» en un numeral independiente, genera tal grado de confusión que para cualquier lector desprevenido el condicionamiento final abarcaba cualquier clasificación del perjuicio al que hiciera mención.

Fuera de eso, como lo define la Real Academia de la Lengua Española, la «y» es una conjunción copulativa «para unir palabras o cláusulas en concepto afirmativo», además de que una de las acepciones de «cláusulas» es la de «conjunto de palabras que, formando sentido completo, encierran una sola oración o varias intimamente relacionadas entre sí» (resalta la Sala), lo que no riñe con la tesis de que la exigencia de que las lesiones por fuera de resarcimiento al distar de una «consecuencia directa de un daño (material o personal)» comprendía al «lucro cesante y los perjuicios patrimoniales puros».

Ahora bien, no pasa desapercibido para la Corte que en la diligencia de exhibición de documentos se aportó un folleto de cláusulas generales de la póliza de vehículos diferente al inicialmente allegado, donde en el numeral 2.14 aparecen como excluidos de amparo «el lucro cesante y los perjuicios patrimoniales puros», añadiendo a punto seguido que «[e]l perjuicio patrimonial puro es la pérdida económica sufrida, que no sea consecuencia de un previo daño personal o material sufrido por el reclamante de dicha pérdida».

Sin embargo, es sustancial la discrepancia de ese texto con las disposiciones que la aseguradora informó al comienzo como regentes de la relación contractual, sin que se justifique la ocurrencia del cambio como resultado de un acuerdo volitivo entre las partes o cualquier otra razón.

\section{COMENTARIO}

Los cargos primero, segundo y cuarto se refieren a la manera como se liquidó el valor de la indemnización, por lo que no serán objeto de comentario en este caso. En consecuencia, se omite incluir las consideraciones de la Corte para los mencionados cargos, teniendo en cuenta que se analiza el tema únicamente en lo que se refiere al contrato de seguro. No obstante lo anterior, estimo importante señalar que tanto el Tribunal en la sentencia de segunda instancia, como la Corte en la sentencia sus- 
titutiva, reducen el ingreso de la víctima (base de la liquidación) en un $50 \%$ por concepto de gastos personales fundado en el hecho de que cada uno de los cónyuges contribuía con el $50 \%$ de los gastos del hogar. La tesis carece totalmente de fundamento en cuanto la proporción aportada a los gastos del hogar no guarda relación alguna con el porcentaje de ingreso aportado. Una persona puede estar destinando el $100 \%$ de sus ingresos para contribuir con el 50\% de los gastos del hogar.

En cuanto al tema de la cobertura de los perjuicios extrapatrimoniales bajo las pólizas de responsabilidad civil de cara a la disposición contenida en el articulo 1127 del Código de Comercio, la Corte deja claramente establecido el alcance de la norma.

Esta misma tesis ha sido sostenida por la Corte en sentencias posteriores reiterando la posición adoptada en la sentencia que se comenta.

Encontramos en idéntico sentido además de la sentencia que se comenta, las siguientes:

Corte Suprema de Justicia. Sala Civil.

SC002-2018.

Enero 12 de 2018.

Radicación: 11001-31-03-027-2010-00578-01.

Aprobado en sesiones del 2, 23 y 30 de agosto y 6 de septiembre de 2017.

Magistrado ponente: Ariel Salazar Ramírez.

Corte Suprema de Justicia. Sala Civil.

Junio 12 de 2018.

Radicación: 11001-31-03-032-2011-00736-01.

Aprobado en sala el 21 de febrero de 2018.

Magistrado ponente: Luis Armando Tolosa Villabona. 
Es procedente concluir entonces, que no es adecuado incluir en los términos y condiciones de las pólizas de seguro de responsabilidad civil la exclusión absoluta de los perjuicios extrapatrimoniales por cuanto con esta estipulación contractual se está desnaturalizando el seguro de RC.

Y en cuanto a la interpretación que debe darse al artículo 1127 del Código de Comercio, la Corte deja claramente establecido el alcance de la norma cuando afirma: "De modo que una interpretación de la regulación del seguro de responsabilidad civil que desconozca, suprima o aminore su función originaria en cuanto a la protección patrimonial del asegurado, desnaturalizaría el contenido esencial de dicho convenio y particularmente la función con la que fue concebido por la ley, en demérito de la confianza que el asegurado deposita al acudir a esa modalidad de aseguramiento."

En la sentencia de junio 12 de 2018, afirma la Corte:

“Así las cosas, la preceptiva soslayada por el juzgador, es la imperante en la solución del sublite por ser exclusiva para los seguros de responsabilidad, la cual contempla la cobertura de los "perjuicios patrimoniales", categoría que comprende lógicamente, todos los menoscabos causados por el asegurado a un tercero, incluyendo los extrapatrimoniales o inmateriales, hasta el límite del valor asegurado, no siendo entonces necesaria la existencia de pacto expreso de esos rubros en la póliza, porque el artículo 1088 antes citado, apenas se refiere a aquello que egresó del patrimonio del asegurado, vale decir, cuanto éste debe indemnizar en su integridad a la vícitma.

"Desconoció entonces la aseguradora, la arquitectura del seguro; pues propuso dicha excepción e irrazonablemente, asi lo aceptó el ad quem. Téngase en cuenta que en el asunto sometido a escrutinio de la Sala, el escenario actual del artículo 1127 del C. de Co., con la reforma introducida por el artículo 84 de la Ley 45 de 1990, las dudas que pudieran existir se han desvanecido íntegramente, pues se estructura con claridad la función que debe cumplir el seguro de responsabilidad civil, sea contractual o extracontractual. (subraya fuera de texto original)

En efecto, alli, y en otros textos, se protegen dos patrimonios: (i) el del asegurado, y (ii) de la víctima como beneficiaria de la indemniza- 
ción, haciéndola titular hoy, inclusive, de una acción directa contra el asegurador, conforme al art. 1113 (sic) del C. de Co. (y también el 1127 ejúsdem) por los daños causados por el asegurado para demostrar en un solo proceso la responsabilidad del asegurado y demandado, y la indemnización del asegurador.

En este último caso, el lesionado deberá acreditar: 1. El contrato de seguro entre asegurador y asegurado que ampara la responsabilidad civil del asegurado; 2. La responsabilidad del asegurado (con apoyo en las reglas 2341 y 2356 del C.C; y no únicamente éstas) frente a la víctima; y 3. La cuantía del perjuicio o magnitud del perjuicio irrogado al damnificado; respondiendo el asegurador, hasta el monto pactado en el negocio jurídico asegurativo, por supuesto.

Sin duda, se protege el interés de los damnificados con el hecho dañoso del asegurado, para resarcirlo, como titular del derecho subjetivo por la realización del riesgo asegurado, haciendo acreedora a la víctima de la prestación. Esta arista del seguro de responsabilidad civil constituye una excepción al principio del efecto relativo de los contratos o principio res inter alios acta ${ }^{25}$, porque beneficia a terceros, la víctima a quien el legislador le otorga, la acción directa para reclamar todo perjuicio irrogado por el asegurado, a pesar de no ser parte del contrato de seguro.

De manera que la aseguradora por imperativo legal asume la obligación de indemnizar los daños provocados por el asegurado, cuando incurre en responsabilidad protegiendo la integridad patrimonial del asegurado, cobijando también los extrapatrimoniales o inmateriales.

25 Los contratos no crean derechos u obligaciones, sino a favor o a cargo de quienes intervinieron como parte del contrato, en este evento el de seguro. 